\title{
Self-Expandable Metal Stents in Palliation of Inoperable Esophageal \& Gastro-Oesophageal Carcinoma
}

\author{
Ahmed A. S. Salem ${ }^{1}$, Ashraf Al-yamany ${ }^{2}$, Esam Abd-el Mohsen ${ }^{3} \&$ Amen H. Zaky ${ }^{2}$ \\ ${ }^{1}$ Lecturer of surgical oncology, South Egypt Cancer Institute, Assiut University, Egypt \\ ${ }^{2}$ Lecturers of Medical Oncology, South Egypt Cancer Institute, Assiut University, Egypt \\ ${ }^{3}$ Lecterur of Internal Medicine, Faculty of Medicine, Assiut University, Egypt \\ Correspondence: Dr. Ahmed Awad Sayed Salem, Lecturer of surgical Oncology and director of endoscopy unit, \\ South Egypt Cancer Institute, Assiut University, Egypt. Tel: 2-088-2347671. Fax: 2-088-2348609. E-mail: \\ ahmed_awad721@yahoo.com
}

Received: March 13, 2012 Accepted: March 26, 2012 Online Published: May 1, 2012

doi:10.5539/cco.v1n1p159 URL: http://dx.doi.org/10.5539/cco.v1n1p159

All authors confirm that they did not receive any funding from or pecuniary interests from any companies

\begin{abstract}
Background: Most of patients with carcinoma of the esophagus are inoperable at the time of presentation. The aim of this study was to evaluate the results of self expandable metal stents for the treatment of malignant dysphagia. Material \& Methods: This study was conducted at Assiut University, Egypt from July 2009 to Dec 2011. Twenty Enrolled patients with grade 3 or 4 dysphagia due to inoperable carcinoma of the esophagus and gastro-oesophageal junction underwent Self Expandable Metal Stenting under endoscopic guidance. They were followed during all the study period. Dysphagia score will be calculated at baseline and at follow up according to Atkinson's scale. Data were analyzed using SPSS version 16. Results: Mean age of patients was $55.5 \pm 15$ years with male to female ratio of 3:2. Mean dysphagia score improved from 3.4 (pre-stent) to 1.07 (post-stent) (p $<0.05$ ). Improvement in dysphagia (conversion of grade 3 or 4 dysphagia into grade 1 or 0 ) was seen in $90 \%$ of patients. Eight patients required re-intervention after initial improvement for their stent blockage (40\%) and two patients followed conservatively for stent migration (10\%). Other minor complications like cough and regurgitation occurred in $10 \%$ and $40 \%$ patients respectively. Most patients experienced severe chest pain necessitating narcotic analgesics. One patient with pulmonary metastasis died within one week, three patients died within 3months, ten patients died within 1.5 years and six patients under flow-up until now. Conclusion: Self expandable metal stents are an effective method for palliation of dysphagia but not without complications.
\end{abstract}

Keywords: esophageal carcinoma, malignant dysphagia, palliation, stent

\section{Introduction}

Cancer of the esophagus is the 9th most common malignancy worldwide and third common amongst gastrointestinal malignancies (Day \& Varghese, 1994; Roohullah et al., 2005). It is the 6th most common cause of cancer deaths universally (Enzinger \& Mayer, 2003; Pisani et al., 1999). Most patients with esophageal cancer present with dysphagia, and more than half the patients have inoperable disease at the time of presentation (Farrow \& Vaughan, 1996; Parkin et al., 2001). The primary aim of treatment in these patients is to relieve dysphagia with minimal morbidity and mortality, and thus improve their quality of life. A number of treatment options are available to relieve dysphagia, including esophageal dilatation, intraluminal stents, Nd: YAG laser therapy, photodynamic therapy, argon laser, systemic chemotherapy, external beam radiation therapy, brachytherapy, and combined chemoradiation therapy. Based on the availability, clinical situation, local expertise, adverse effects, cost of treatment and patient preference, either one or a combination of modalities can be used for the relief of dysphagia (Javle et al., 2006; Minsky, 2006). In recent times, placement of a selfexpanding metal stent (SEMS) has become established as a treatment modality for the palliation of malignant dysphagia as it relieves dysphagia rapidly and improves the nutritional status of the patient (Weigel et al., 2002; Xinopoulos et al., 2004). 
The major disadvantages of SEMS include high cost, tumor in-growth, and relatively common acute and late complications, including chest pain, regurgitation, cough and foreign body sensation, stent migration, blockage and hemorrhage (Ell \& May, 1997).

The aim of this study was to evaluate the results of esophageal SEMS for the treatment of malignant dysphagia.

\section{Patients and Methods}

This a prospective study was conducted at Surgical Oncology Department, South Egypt Cancer Institute, Assiut University, Egypt from July 2009 to Dec 2011. Informed consent was given by every patient who participated in this study, and the study was approved by our ethical committee. Patient's characteristics are given in table 1.

Table 1. Characteristics of the patients

\begin{tabular}{ll}
\hline & Number(\%) \\
\hline Total number of patients & 20 \\
Male & $12(60)$ \\
Female & $8(40)$ \\
Mean age (years) & $55.5 \pm 15$ \\
Mean dysphagia grade & 3.4 \\
Site of lesion & \\
Mid esophagus & $13(65)$ \\
Lower esophagus & $7(35)$ \\
Tumor histology & \\
Squamous cell carcinoma $10(77)$ & $14(70)$ \\
Adenocarcinoma & $6(30)$ \\
\hline
\end{tabular}

All patients presenting with dysphagia underwent a thorough history and physical examination. Upper GI endoscopy and biopsy was done to confirm the diagnosis. Imaging studies (Chest X-ray, Ultrasound abdomen and Computed Tomography (CT) scan chest and abdomen) were done to assess local and distant disease extent. Dysphagia was graded according to Atkinson's score: grade 0: ability to eat normal diet; grade 1: ability to eat some solid food; grade 2: ability to eat some semisolid food; grade 3: ability to swallow liquids only; and grade 4: complete obstruction.

We used uncovered stents in all patients (Boston Scientific). The inner diameter of the central portion of the stent is $17-18 \mathrm{~mm}$ when fully expanded. The ends of the stent measure $28 \mathrm{~mm}$ in diameter. They are flanged to facilitate anchoring of the stent to the esophageal wall. A $39 \mathrm{~F}(13 \mathrm{~mm})$ delivery system is used for insertion of the stent and consists of three coaxially arranged polypropylene tubes. The stent is preloaded on the inner tube while the outer tube compresses the stent. The central lumen of the inner tube allows guide wire insertion.

\section{Technique of Stent Insertion}

The procedure was performed under local anesthetic spray, with intravenous sedation. We used uncovered stents in all patients. Stents were inserted under endoscopic guidance. First upper gastrointestinal endoscopy was performed to delineate the site and length of stricture with patient placed in the left lateral position. To facilitate rapid expansion of stent; dilatation was done in all patients up to $15 \mathrm{~mm}$ with Savary Gilliard dilators. Proximal and distal margin of tumor or stricture site was determined with scope in situ. Length of stent was chosen so that at least $2.5 \mathrm{cms}$ of normal esophagus was covered above and below the stricture. The guide wire was inserted through the stricture via an endoscope, and the stent system was passed over it, released and deployed. Position of stent was confirmed endoscopically at the end of the procedure.

Oral liquids were allowed $4 \mathrm{~h}$ after the procedure, and then gradually increased to semi-solids and then to solids over the next $24 \mathrm{~h}$. postoperatively. A chest X-ray was taken to exclude perforation and check the stent position. All Patients were kept in hospital for 24 hours and then discharged if there were no complications. They were 
then followed up weekly for one month. At each follow up visit symptoms of complications of stent and dysphagia score of each patient were determined.

\section{Results}

Mean age of patients was $55.5 \pm 15$ years with male to female ratio of 3:2. Mean dysphagia score improved from 3.4 (pre-stent) to 1.07 (post-stent) $(\mathrm{p}<0.05$ ). Improvement in dysphagia (conversion of grade 3 or 4 dysphagia into grade 1 or 0 ) was seen in $90 \%$ of patients.

Data was analyzed by statistical software SPSS version 16. Chi-square test was used for comparison of pre and post stent mean dysphagia score. A p-value of $<0.05$ was considered significant.

Twenty patients with grade 3 and grade 4 dysphagia due to inoperable carcinoma esophagus \& cardio-oesophageal junction, either because of locally advanced disease (eight patients), distant metastasis (six patients), co-morbidities (two patients) or poor general health status (four patients), were included in the study. Patients with carcinoma of cervical esophagus were excluded due to lack of our experience at this site.

SEMS placement was technically successful in all 20 patients (100\%). Dilatation was needed in all patients. Swallowing was improved in 19 of 20 patients (95\%). Mean dysphagia score before implantation was 3.4 which significantly improved to 1.07 after SEMS placement $(P<0.05)$. Perforation never occurred. Eight patients had their SEMS blocked; six are due to food bolus impaction (Figure 1,2), and the other two because of tumor in-growth tumor in-growth was successfully managed by inserting another SEMS under endoscopic guidance in one patient and repeated dilation in the other patient who developed stenosis at the mouth of the stent (Figure 3,4 ), while food bolus obstruction was cleared endoscopically Stent misplacement occurred in two patients which was treated with conservative follow-up (Table 2).

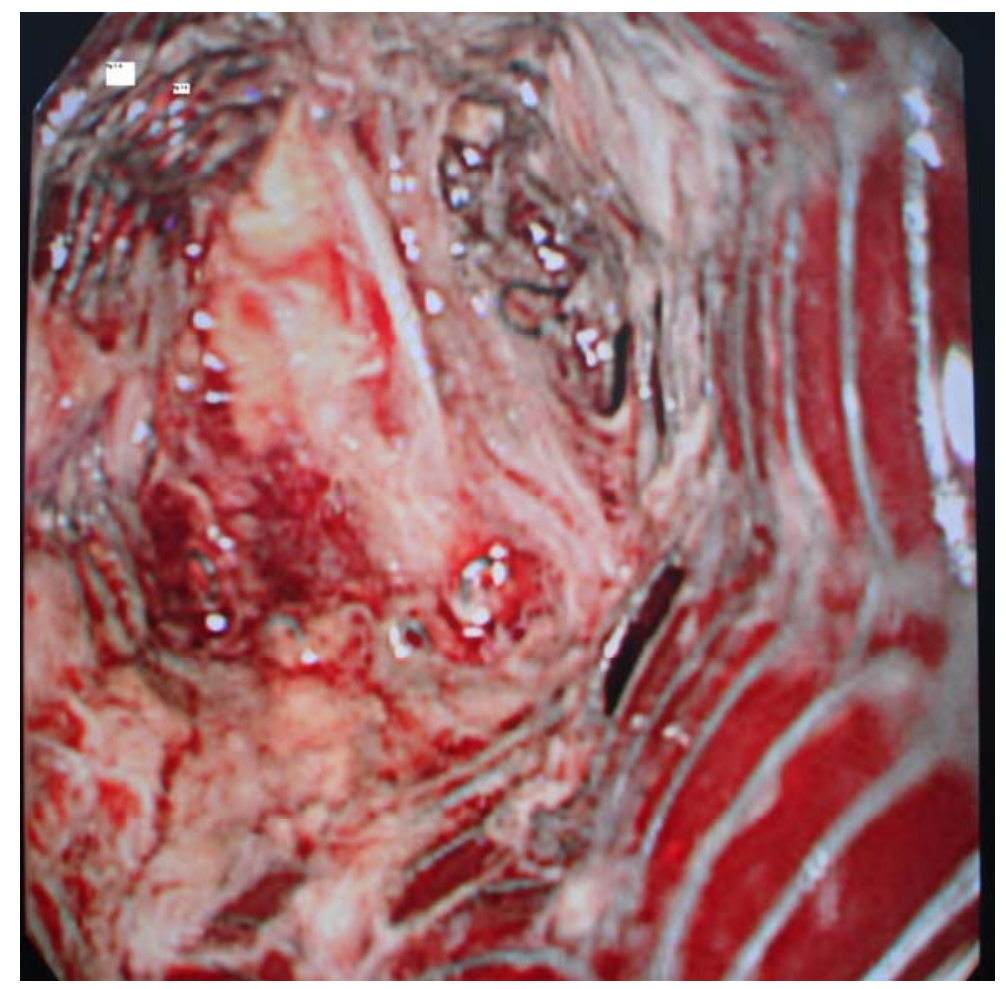

Figure 1. Stent blockage by food particle 


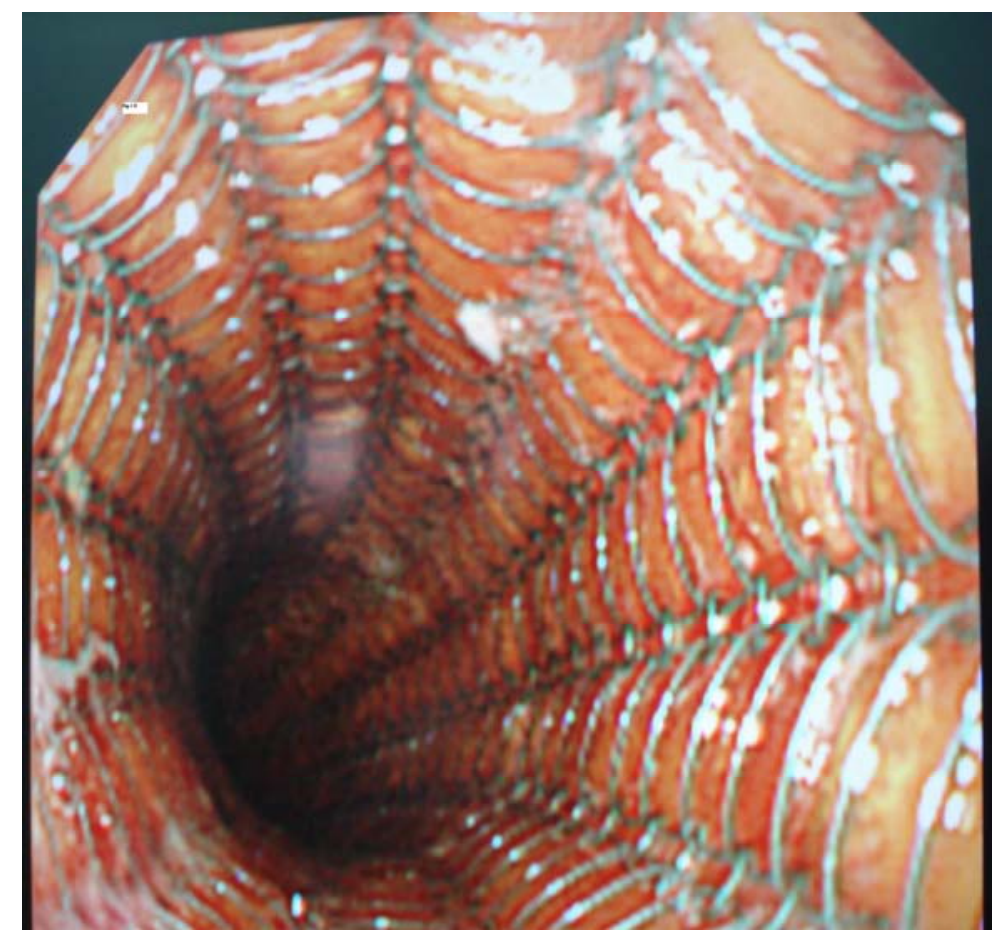

Figure 2. Patency was re-established by saline wash out

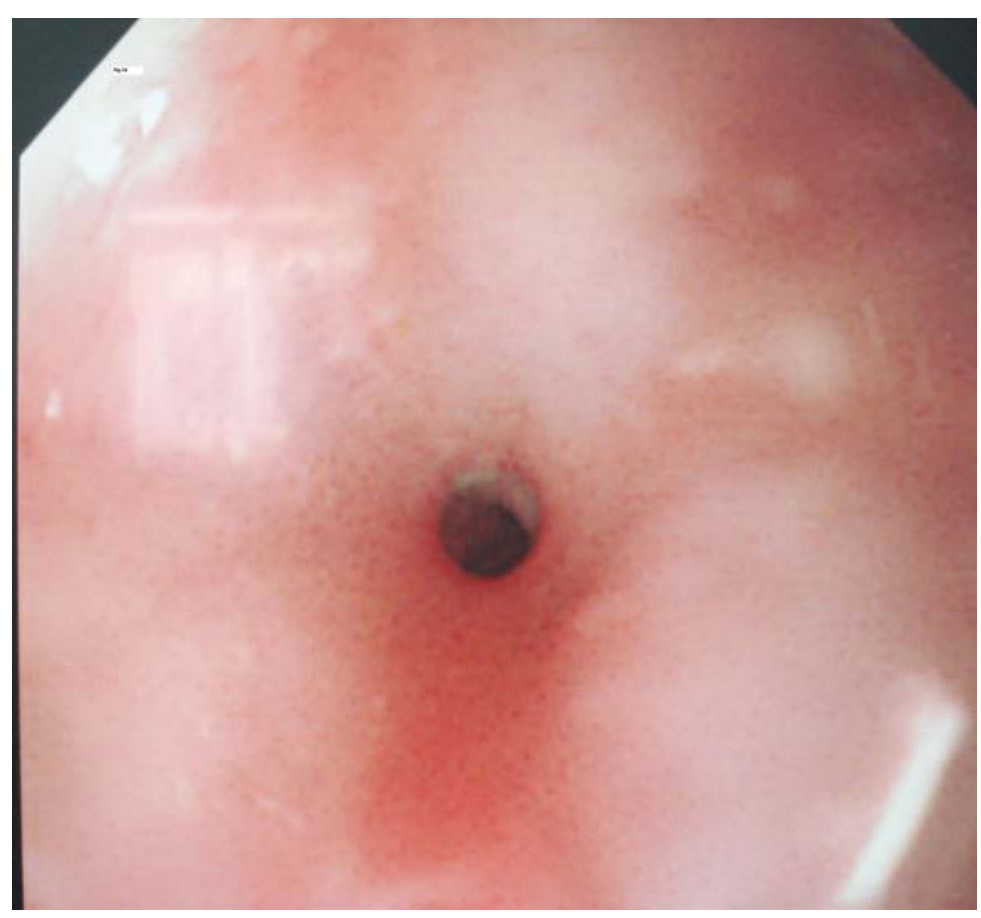

Figure 3. Stenosis at the mouth of stent 


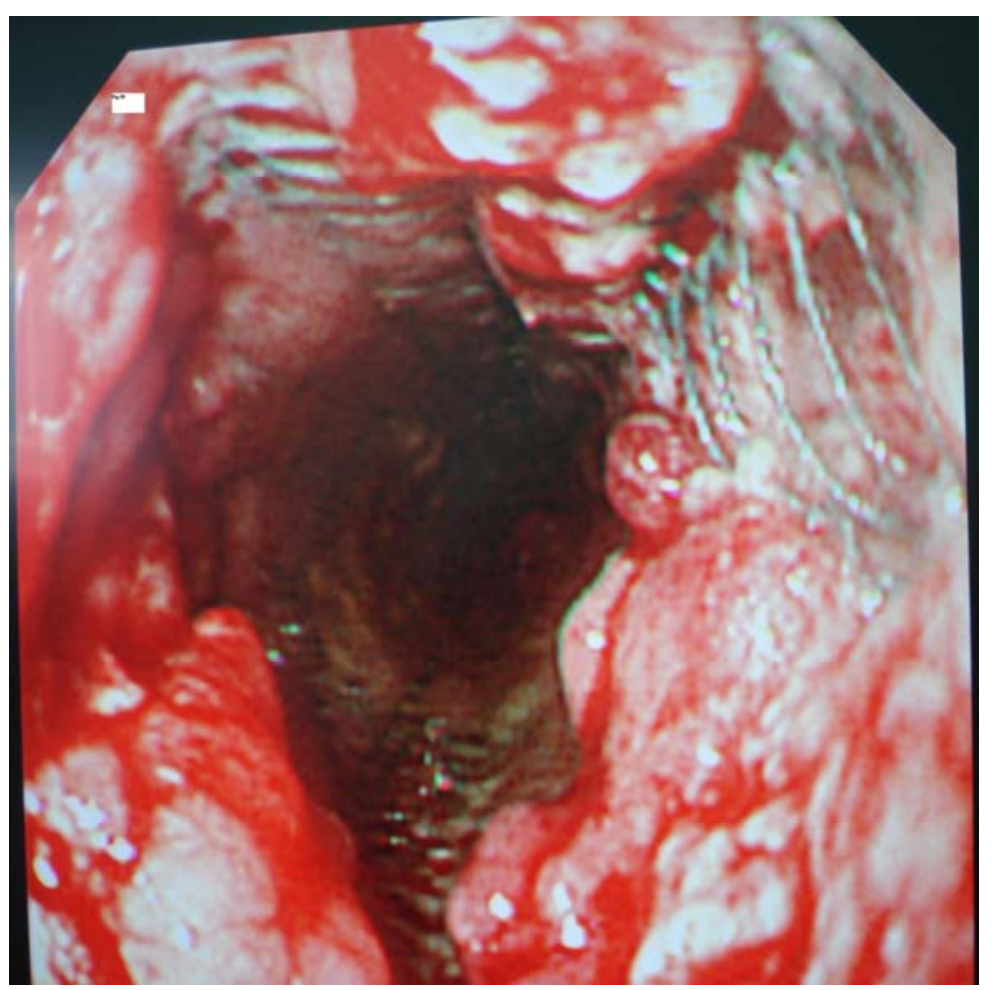

Figure 4. Re-opening by dilatation

Table 2. Complications following SEMS placement

\begin{tabular}{ll}
\hline Complication & Number (\%) \\
\hline Cough and foreign body sensation & $4(20)$ \\
GERD & $8(40)$ \\
Pain requiring narcotic analgesics & $12(60)$ \\
Stent block & $8(40)$ \\
Perforation & $0(0)$ \\
Misplacement & $2(10)$ \\
\hline
\end{tabular}

\section{Discussion}

Esophageal cancer is the sixth leading cause of death from cancer worldwide (Enzinger \& Mayer, 2003; Pisani et al., 1999). More than $50 \%$ of patients with esophageal cancer are not amenable to surgical excision at the time of diagnosis, either because of advanced disease or due to the presence of co morbid conditions. 6 Dysphagia is the most common presenting symptom of this disease and leads to nutritional compromise, pain, and deterioration of quality of life. Palliation of dysphagia is the mainstay of treatment for such patients.

Although plastic prostheses have been shown to be efficacious, gross dilatation of the tumor stenosis was necessary to enable the passage of these tubes. Consequently, the rate of gross esophageal rupture at the tumor site, as well as aspiration, reflux, pneumonia, and sepsis was high with a mortality rate of up to $42 \%$ (Stemerman et al., 1997; Buess et al., 1988; Cusumano et al., 1992). SEMS have recently been introduced to rectify this drawback. Self-expanding metallic stents provide a substantial progress in the management of patients with inoperable carcinoma of esophagus. SEMS are made up of an alloy; usually nitinol or stainless steel. They are deployed using endoscopic and/ or fluoroscopic techniques and quickly restore esophageal patency and effectively relive dysphagia (Espinel et al., 2006).

Self-expandable metallic stent (SEMS) placement has been widely accepted to be an effective option for palliation of the symptoms caused by malignant esophageal strictures. Several studies have reported excellent results in relief of dysphagia using SEMS, with a technical success rate of $100 \%$ and clinical success rate of $83 \%$ 
to $100 \%$ (Sabharwal et al., 2003; Laasch et al., 2002; Vakil et al., 2001; Siersema, 2001; Lightdale, 2000; McCaughan et al., 1996). Our study shows similar results with a technical success rate of $100 \%$ and relief of dysphagia in $95 \%$ of patients. Mean dysphagia score significantly improved from 3.4 (pre-stent) to 1.07 (poststent).

Although SEMS are effective and easier to place, they are not without complications. One of the main complications of metal stents is distal migration, with an incidence rate ranging between $10 \%$ and $30 \%$ (Cowling et al., 1998). It is more commonly (50\%) seen when covered stents are used to treat distal esophageal lesions involving the gastroesophageal junction (Warren WH, 2000; Loizou et al., 1991). In our study stent migration occurred in $10 \%$ patients which was managed successfully by conservative follow-up.

Stents blockage is another problem with uncovered stents. It is due to tumor in-growth (17-36\%) or overgrowth $(10 \%)$ and food bolus obstruction leading to recurrence of dysphagia (Rozanes et al., 2002; McGrath et al., 2001). Two of our patients blocked their stents (10\%), because of tumor in-growth and the other six are due to food bolus impaction. Tumor in-growth was successfully managed by inserting another stent and food bolus was cleared endoscopically. Perforation is more serious complication in patients with malignant dysphgia, and mortality rate is high. The incidence of perforations is more than $10 \%$ for plastic stents (Stemerman et al., 1997; Buess et al., 1988; Cusumano et al., 1992) compared with less than 5\% in SEMS (Watkinson et al., 1995). This rate was $0 \%$ in our series. Hematemesis is also a possible complication after SEMS insertion (Wu et al., 1994). It is due to pressure necrosis, the natural progress of the disease, or trauma from the sharp, uncovered end of the stent (Vermeijden et al., 1995). Although its incidence is reported to be up to 5\% (Shields SJ, 1997), none of our patients had hemetemesis. Chest pain is a common complaint following stent insertion, with a reported incidence of up to $100 \%$ (Acunas et al., 1996). It is usually due to dilatation and stretching. In our study $60 \%$ patients complained of severe retero-sternal chest pain necessitating narcotic analgesics.Regurgitation is a frequent complication of esophageal stenting and is more common in patients who undergo stenting for lesions in the lower esophagus (72\%) (Madhusudhan et al., 2009), which was $40 \%$ in our series and was managed with Proton Pump Inhibitors. Other minor complications like foreign body sensation and cough were also seen in our patients.

\section{Conclusion}

All kinds of endoscopic methods used for stenting were easy to perform even on an out-patient basis. SEMS insertion is an effective way of relieving dysphagia in patients with inoperable carcinoma esophagus but it is not without complications. Their high cost, high complication rates and low overall survival may improve following better selection criteria.

\section{Acknowledgments}

The corresponding author much appreciate and acknowledge the time and effort of doctor Kenji Yamao, Director of the department of gastroenterology ,Aichi Cancer Center, Nagoya, Japan, who was his supervisor during his scholarship in Japan during the period from 2004-2006.

\section{References}

Acunas, B., Rozanes, I., Akpinar, S., Tunaci, A., Tunaci, M., \& Acunas, G. (1996). Palliation of malignant esophageal strictures with self expanding nitinol stents, drawbacks and complications. Radiology, 199, $648-52$.

Buess, G., Schellong, H., Kometz, B., Grubner, R., \& Junginger, T. H. (1988). A modiûed prothesis for the treatment of malignant esophagotracheal ûstula. Cancer, 61, 1679-84. http://dx.doi.org/10.1002/1097-0142 (19880415)61:8<1679::AID-CNCR2820610828>3.0.CO;2-X

Cowling, M. G., Hale, H., \& Grundy, A. (1998). Management of malignant oesophageal obstruction with selfexpanding metallic stents. Br J Surg, 85, 264-6. http://dx.doi.org/10.1046/j.1365-2168.1998.00562.x

Cusumano, A., Rual, A., \& Segalin, A. (1992). Push through intubation, effective palliation in 409 patients with cancer of the esophagus and cardia. Ann Thorac Surg, 53, 1010-4. http://dx.doi.org/10.1016/0003-4975(92) 90376-F

Day, N. E., \& Varghese, C. (1994). Oesophageal cancer. Cancer Surv, 19-20, 43-54.

Ell, C., \& May, A. (1997). Self-expanding metal stents for palliation of stenosing tumors of the esophagus and cardia, a critical review. Endoscopy, 29, 392-8. http://dx.doi.org/10.1055/s-2007-1004222

Enzinger, P. C., \& Mayer, R. J. (2003). Esophageal cancer. $N$ Engl J Med, 349, 2241-52. http://dx.doi.org/10.1056/NEJMra035010 
Espinel, J., Sanz, O., Vivas, S., Jorquera, F., Manzo, F., Olcoz, J. L., et al. (2006). Malignant gastrointestinal obstruction,endoscopic stent versus surgical palliation. Surg Endosc, 20, 1083-7. http://dx.doi.org/10.1007/ s00464-005-0354-8

Farrow, D. C., \& Vaughan, T. L. (1996). Determinants of survival following the diagnosis of esophageal adenocarcinoma (United States). Cancer Causes Control, 7, 322-7. http://dx.doi.org/10.1007/BF00052937

Javle, M., Ailawadhi, S., Yang, G. Y., Nwogue, C. E., Schiff, M. D., \& Nava, H. R. (2006). Palliation of malignant dysphagia in esophageal cancer, a literature based review. J Support Oncol, 4, 365-73.

Laasch, H. U., Marriott, A., Wilbraham, L., Tunnah, S., England, R. E., \& Martin, D. F. (2002). Effectiveness of open versus antireûux stents for palliation of distal esophageal carcinoma and prevention of symptomatic gastroesophageal reûux. Radiology, 225, 359-65. http://dx.doi.org/10.1148/radiol.2252011763

Lightdale, C. J. (2000). Role of photodynamic therapy in the management of advanced esophageal cancer. Gastrointest Endosc Clin N Am, 10, 397-408.

Loizou, L. A., Grigg, D., Atkinson, M., Robertson, C., \& Bown, S. G. (1991). A prospective comparison of laser therapy and intubation in endoscopic palliation for malignant dysphagia. Gastroenterology, 100, 1303-10.

Madhusudhan, C., Pal, S., Ahuja, V., Saran, P., Sahni, P., et al. (2009). Diseases of Esophagus, 22, 331-6. http://dx.doi.org/10.1111/j.1442-2050.2008.00906.x

McCaughan, J. S. Jr., Ellison, E. C., Guy, J. T., et al. (1996). Photodynamic therapy for esophageal malignancy,a prospective twelve-year study. Ann Thorac Surg, 62, 1005-9. http://dx.doi.org/10.1016/0003-4975(96)005 $63-2$

McGrath, J. P., Browne, M., \& Riordan, C. (2001). Expandable metal stents in the palliation of malignant dysphagia and oesophageal respiratory ûstula. Ir Med J, 94, 270-2.

Minsky, B. D. (2006). Choosing the correct modality for the treatment of dysphagia in the patient with esophageal cancer. J Support Oncol, 4, 377.

Parkin, D. M., Bray, F., Ferlay, J., \& Pisani, P. (2001). Estimating the world cancer burden, Globocan 2000. Int J Cancer, 94, 153-6. http://dx.doi.org/10.1002/ijc.1440

Pisani, P., Parkin, D. M., Bray, F., \& Ferlay, J. (1999). Erratum, Estimates of the worldwide mortality from 25 cancers in 1990. Int J Cancer, 83, 870-3. http://dx.doi.org/10.1002/(SICI)1097-0215(19991210)83:6<870:: AID-IJC35>3.0.CO;2-9

Roohullah, Khursheed, M. A., Shah, M. A., Khan, Z., Haider, S. W., Burdy, G. M., et al. (2005). An alarming occurrence of esophageal cancer in Balochistan. Pak J Med Res, 44, 101-4.

Rozanes, I., Poyanli, A., \& Acunas, B. (2002). Palliative treatment of inoperable malignant esophageal strictures with metalstents, one center's experience with four different stents. Eur J Radiol, 43, 196-203. http://dx.doi.org/10.1016/S0720-048X(02)00154-7

Sabharwal, T., Hamady, M. S., Chui, S., Atkinson, S., Mason, R., \& Adam, A. (2003). A randomized prospective comparison of the FlamingoWallstent and Ultraûex stent for palliation of dysphagia associated with lower third oesophageal carcinoma. Gut, 52, 922-6. http://dx.doi.org/10.1136/gut.52.7.922

Shields, S. J. (1997). Esophageal self-expandable metallic stents. Gastrointest Endosc, 45, 439-42. http://dx.doi.org/10.1016/S0016-5107(97)70163-9

Siersema, P. D., Schrauwen, S. L., van Blankenstein, M., et al. Rotterdam Esophageal Tumor Study Group. (2001). Self-expanding metal stents for complicated and recurrent esophagogastric cancer. Gastrointest Endosc, 54, 579-86. http://dx.doi.org/10.1067/mge.2001.118716

Stemerman, D. H., Caroline, D. F., Dabezies, M., Mercader, V. P., Krevsky, B., \& Gatenby, R. A. (1997). Non-expandable silicone esophageal stents for treatment of malignant tracheoesophageal ûstulas,complications and radiographic appearances. Abdom Imaging, 22, 14-9. http://dx.doi.org/10.1007/s002619900131

Vakil, N., Morris, A. I., Marcon, N., et al. (2001). A prospective, randomized, controlled trial of covered expandable metal stents in the palliation of malignant esophageal obstruction at the gastroesophageal junction. Am J Gastroenterol, 96, 1791-6. http://dx.doi.org/10.1111/j.1572-0241.2001.03923.x 
Vermeijden, J. R., Bartelsman, JFWM, Fockens, P., Meijer, R. C. A., \& Tytgat, G. N. J. (1995). Self-expanding metal stents for palliation of esophageal malignancies. Gastrointest Endosc, 41, 58-63. http://dx.doi.org/10.1016/S0016-5107(95)70277-6

Warren, W. H. (2000). Palliation of dysphagia. Chest Surg Clin N Am, 10, 605-23.

Watkinson, A. F., Ellul, J., Entwisle, K., Mason, R. C., \& Adam, A. (1995). Esophageal carcinoma, initial results of palliative treatment with covered selfexpanding endoprostheses. Radiology, 195, 821-7.

Weigel, T. L., Frumiento, C., \& Gaumintz, E. (2002). Endoluminal palliation for dysphagia secondary to esophageal carcinoma. Surg Clin North Am, 82, 747-61. http://dx.doi.org/10.1016/S0039-6109(02)00037-3

Wu, W. C., Katon, R. M., Saxon, R. R., Barton, R. E., Uchida, B. T., Keller, F. S., \& Rosch, J. (1994). Silicone-covered self expanding metallic stents for the palliation of malignant esophageal obstruction and esophagorespiratory fistulas, experience in 32 patients and a review of the literature. Gastrointest Endosc, 40, 22-33. http://dx.doi.org/10.1016/S0016-5107(94)70005-2

Xinopoulos, D., Dimitroulopoulos, D., Moschandrea, I., et al. (2004). Natural course of inoperable esophageal cancer treated with metallic expandable stents, quality of life and cost-effectiveness analysis. $J$ Gastroenterol Hepatol, 19, 1397-402. http://dx.doi.org/10.1111/j.1440-1746.2004.03507.x 